Emotion regulation beyond appraisals: Other routes to sustained and changed intergroup feelings

Roger Giner-Sorolla

Aleksandra Cichocka

University of Kent

Draft: 28 February 2016 
Corresponding author: Roger Giner-Sorolla, University of Kent. School of Psychology,

Canterbury, Kent, CT2 7NP, United Kingdom, e-mail rsg@kent.ac.uk 


\section{Emotion regulation beyond appraisals: Other routes to sustained and changed intergroup feelings}

Given the importance of emotions in intergroup relations, we were delighted to read the target article, which promises to integrate a wide variety of findings on the dynamics of group-relevant emotions. Indeed, it was inspiring to see research on such a rich variety of emotions and contexts brought together and reviewed. We particularly appreciated the dynamic nature of the theoretical model, which emphasized how changes in appraisals might lead to improved relations, rather than simply explaining problematic emotions. It is with appreciation for this optimism that we nonetheless wish to point out additional considerations that stem from our existing theory and empirical writings. Specifically, although a focus on appraisals leads to suggestions that facilitate change, we feel that other functions of emotions rooted in their stable, defensive, and communicative nature have to be viewed with

understanding as well. Ĉehajić -Clancy, Goldenberg, Gross, and Halperin (this issue) propose a process model with a number of stages at which emotions can be regulated. They believe, as we do, that changing emotions can often be critical to motivating new ideas and behaviors about any given intergroup conflict. The stage focused on, and for which they have the most plentiful evidence in support, is the appraisal stage. Here, people are motivated to accept new propositional statements about themselves (e.g., reappraising their identity) or about the situation their group finds itself in (e.g., believing that a resolution to a conflict is possible). It is important to note that this process is not necessarily motivated by a wish to change one's own emotions directly but can have other motivations that indirectly lead to change in emotions.

\section{Why Change? Insights from Motivation Theory}

The target model is supported by an impressive number of experiments targeting various emotions and showing that inducing changes in appraisals can induce changes in shortterm 
emotions, long-term sentiments, and associated behavioral intentions. However, in its details we see this as primarily a process model that, although valuable, largely elides the question of why people are motivated to change. As an old joke goes, "How many psychotherapists does it take to change a lightbulb? Only one, but the lightbulb has to really want to change." The reliance on experimental method to support the model has led to good causal inferences about the influence of changed appraisals, but we are left wondering under what conditions people might resist this influence - as some surely do — and when they would generate this change of appraisals themselves, without experimental input, in order to qualify as a truly selfregulatory process.

A related issue: In proposing that emotion regulation need not be accompanied by a conscious desire to change the emotion, this model sidesteps important motivational features common to most models of self-regulatory process. We think that even if unconscious, these features deserve attention, because only they can explain why people ultimately might change their appraisals, whether through social influence or of their own accord.

Some self-regulation models cover progress toward a single goal (Carver \& Scheier, 1990; Higgins, 1987), stating that selfregulatory processes are invoked in particular when progress toward a goal is difficult or blocked. This suggests, then, that appraisals are particularly likely to change when the goals they support become seen as difficult or impossible to achieve. In intergroup situations, these goals may be as diverse as finding peace, security, dominance, or revenge when faced with another group. Particularly important is work on individuallevel self-regulation examining when effort toward goals is redoubled, versus abandoned, in the face of failure (Jostmann \& Koole, 2009). Finding this tipping point would seem to be critical in the case of convincing people to abandon collective goals that served them well during years of conflict. Other theories of self-regulation point out that in any situation, humans are likely to have a multiplicity of goals that can support or conflict with each other. Often these 
goals are arranged in some kind of hierarchy whether conceived of as existing on different construal levels (e.g. Vallacher \& Wegner, 1987), as "goals" versus "temptations" in selfcontrol (Fujita, Trope, Liberman, \& Levin-Sagi, 2006; Myrseth \& Fishbach, 2009), or as systems in which some goals are privileged over others (Shah, 2005). One answer to the question of why people in difficult conflicts may want to change, then, is that the existence of other goals than the conflict-related goal takes precedence, and the regulatory priority of these new goals forces new appraisals and feelings into existence.

In intergroup situations, an obvious source of hierarchical conflicting goals are the different levels of social organization an individual sees themselves as belonging to. A single person may think and feel as an individual; a family member; a denizen of a town, city, or region; a national citizen; or globally as a human being, not ignoring also the many subtleties of sexual, ethnic, and social class identification. Goals competing with a dysfunctional nationlevel narrative can be found by looking downward in this goal hierarchy (as we see when individual self-affirmation produces more open-minded change than collective selfaffirmation does; Ĉehajić et al., 2011). In theory it can also be found by looking upward, as when individuals are asked to consider common humanity or superordinate group identification (Gaertner \& Dovidio, 2000; Greenaway, Quinn, \& Louis, 2011; Morton \& Postmes, 2011).

However, we suspect that when seeking to change emotions, the more powerful motivations are to be found looking downward, toward more concrete and personal interests and connections. Collective guilt, for example, should be felt when people consider how their group has wronged others in the past, from the point of view that all groups belong to the human community. However, a fairly consistent finding in the intergroup emotions field is that collective guilt is a weak presence and motivator (Leach, Zeineddine \& Cehajić -Clancy, 2013), especially when compared to shame, which can be seen as amore ingroup-focused 
emotion that seeks to change the perception and reality of the ingroup's morality (Allpress, Brown, Giner-Sorolla, Deonna, \& Teroni, 2014; Lickel, Steele, \& Schmader, 2011).

\section{Why Resist Change? Insights from Emotion Theory}

Emotions are also more complicated than this theory lets on. There is ample evidence, reviewed in Giner-Sorolla (2012), that appraisal theory does not give a complete explanation for why we have emotions, although it does give an important one. Appraisal alone cannot explain why we communicate emotions, often without the intention or desire to do so, when individuals should benefit from only showing their motivations when they want to. It cannot completely explain the existence of the long-term sentiments described in the target article, emotions that have become associated with a person, object, or group; why do these feelings persist even in the face of appraisal evidence that they might be irrational, as in phobia or blind patriotism? It also cannot explain why emotions, which should follow and serve cognition, instead lead at times. Often, we think and act in less than optimal ways to enjoy good feelings and avoid unpleasant ones. This is true especially when the object of those feelings is the self or, by extension, the ingroup. The common answer to all of these riddles derives from the insight of Frank (1988) that emotions may appear irrational in a given situation because they act as commitment devices that bind individuals to actions that are rational on a longer term or a larger social scale. The functional conflict theory of emotions presented by Giner-Sorolla (2012) outlines three functions that emotions serve, in addition to and in conflict with appraisal of a present situation.

\section{Associative Function}

The associative function, source of the aforementioned intergroup sentiments, encodes links between objects (including social groups) and emotion in a way that resists modification by context. When people, even against their best judgment and interest, feel pride at their national anthem or disgust at a stigmatized minority group, the associative function is in play. 
Emotions also have associative influences beyond appraisal when an emotion from one situation carries over into another; for example, when anger from a single example of injustice influences moral judgments more generally (Goldberg, Lerner, \& Tetlock, 1999), which also shows emotion behaving in a way that ignores context.

In intergroup relations, specific emotions related to intergroup prejudice (the "sentiments" mentioned in the target article) have been shown both to transfer to unrelated contexts and to be affected by unrelated factors, such as an individual's proneness to feel that emotion in nonsocial situations. This has been demonstrated particularly for the emotion of disgust (Hodson \& Costello, 2007; Inbar, Pizarro, Knobe, \& Bloom, 2009; Tapias, Glaser, Keltner, Vasquez, \& Wickens, 2007). Also, recent evidence shows that people who are more prone to implicitly associate positive versus negative emotions with their national identity respond with greater prejudice against outgroups when presented with polarizing national symbols (Finell \& Zogmaister, 2015). Although associative processes may have their roots in an evolutionary need to take quick and unconditional action regarding threats and opportunities, in a larger social sense these unconditional and unjustifiable feelings (toward symbols of the nation for example, or toward scapegoated groups) serve as a sign of socialization and coordination that cannot be overridden by individual, rational concerns.

In the context of improving intergroup relations, too, similar processes involving positive emotional transfer have been observed in a series of studies examining attitudes toward Native American policies among non-Native Americans (Greenaway, Cichocka, van Veelen, Likki, \& Branscombe, 2016a). Both measured and experimentally manipulated general feelings of hope fostered greater support for efforts to increase equality between Native and non-Native Americans, and these effects were mediated by a belief that the advantaged group can work to achieve equality. This research suggests that emotions can 
affect intergroup attitudes, even if they are experienced independently of the intergroup context. Overall, although by no means a complete account, the literature reviewed here shows that nonemotional associative transference offers both obstacles to improving intergroup relations (as in the case of prejudice) and pathways to doing so (as in the case of hope).

\section{Self-Regulatory Function}

The self-regulatory function of emotions, too, is more complicated than a mere goal-related appraisal account allows for. Although it is true that emotions toward the self (or ingroup) can change in response to appraisals of the self (or ingroup) making progress toward goals, it is also true that these emotional states can take on a life and motivation of their own, such that thought and behavior are selectively chosen to uphold a desired emotional state. In general, it seems that any kind of positive emotional state, or negative states focused externally such as anger or disgust, is preferred over emotional states that imply negative evaluation of one's self in terms of security or morality, such as anxiety, fear, guilt, or shame. Although this might also be seen as a misfire of evolution - the primary reinforcer overcoming the long-term reasons for its own existence- there may be emergent group-based reasons to prefer emotions that help to coordinate both internally helpful and externally hostile action, without questioning too much the integrity of the group itself.

At the group level of analysis, the regulatory function will likely depend on specific ways people identify with their ingroup. For instance, some people develop a narcissistic investment in an unrealistic belief in the ingroup's greatness. This has been described as collective narcissism - a type of ingroup positivity associated with the need to constantly validate and protect the image of the ingroup (Golec de Zavala, Cichocka, Eidelson, \& 
Jayawickreme, 2009). Collective narcissism is linked to sensitivity to threats as well as hostile reactions to any signs of criticism that might undermine the ingroup image (see, e.g., Cichocka, Marchlewska, Golec de Zavala, \& Olechowski, 2015; Golec de Zavala \& Cichocka, 2012; Golec de Zavala, Cichocka, \& Iskra-Golec, 2013). Such defensive ingroup positivity might have important consequences for attempts to trigger critical moral emotions (such as group-based guilt) by increasing perceptions of the ingroup's responsibility for past wrongdoings. As Cehajić-Clancy et al. (this issue) admit, the "acknowledgement of in-group responsibility is rather rare" (p. 8), and this might largely depend on the type and strength of ingroup identification.

Research conducted in Israel by Roccas, Klar, and Liviatan (2006) indicates that glorifying the Israeli ingroup is associated with greater likelihood of coming up with excuses minimizing the ingroup's responsibility for harmful actions against the Palestinians and less feelings of group-based guilt (see also Leidner, Castano, Zaiser, \& Giner-Sorolla, 2010). Complementary examples stem from research on reminders of ingroup wrongdoings conducted in Poland. For instance, angry protests followed publication of books reporting instances of anti- Semitism in Poland by Jan Tomasz Gross. A prevalent feeling has been that the books are a misrepresentation and a consequence of anti-Polish propaganda. Recently, there have even been attempts to strip the author of the national honor (Duval Smith, 2016). Research indicates that such reactions are especially strong among those high in Polish collective narcissism (see Cichocka, Golec de Zavala, Marchlewska, \& Olechowski, 2015). Ceehajić -Clancy et al. (this issue) discuss positive intergroup contact as one way by which we can facilitate acceptance of ingroup responsibility, but the need to protect the ingroup and increased threat perceptions among those high in collective narcissism (or ingroup glorification) might lead them to be less willing to engage in intergroup contact and, importantly, experience negative emotions 
during intergroup interactions. We see greater hope in the research cited on selfaffirmation that might reduce defensiveness not only at the individual but also at the collective level (Ĉehajić -Clancy, Effron, Halperin, Liberman, \& Ross, 2011), potentially decreasing narcissistic in-group positivity (Cichocka et al., 2016).

However, we should add that on a theoretical level, the effectiveness of individual selfaffirmation is hard to explain through appraisal theory alone, because it does not touch on the present context. Also, in this research group, self-affirmation that does touch on the present context did not have any effect to loosen defensiveness. Only a theory of motivated self-regulation that puts feelings before appraisals, such that improving feelings about the self can reduce a defensive need to cling to positive feelings about the group, can explain the special effects of a type of affirmation that reaches across individual and collective contexts.

\section{Communicative Function}

Finally, emotions through their many expressive features enable social communication, a function that has been strongly supported by theoretical perspectives and empirical evidence alike (for a review, see Giner-Sorolla, 2012). Although to some extent emotional communications can be regulated, this is not always possible, and the spontaneous and uncontrollable nature of emotions makes them useful as social commitment devices - whereby we can judge the tenacity of an adversary, the faithfulness of a partner, or the sincerity of an affirmation through more than just their self-interested say-so. In social contexts, too, an important determinant of our emotions is what we wish to express to other people. As with the other two non-appraisal functions, the communication function can be seen as larger scale social regulation, both by underscoring the demands of the individual on the group and by enforcing the 
conformity of the individual's emotion expressions with group norms. Indeed, it is currently recognized that regulation of other people's emotions - to reach a desired goal, or to more directly achieve conformity and consensus - is an important part of social life. Certainly, social input should be considered as a reason both why people might change and why they might resist change.

Although research on strategic expressions of emotions in the intergroup context is scarce, there is preliminary evidence that emotional expressions can be used in social regulation of emotions felt between groups. For instance, research by Greenaway, Cichocka, van Veelen, Likki, and Branscombe (2016b) demonstrates that expressions of hope by the disadvantaged group can encourage members of the advantaged group to take action to increase social equality. In a context more directly related to the reconciliation process, participants perceived reparations offered by outgroup members as less insulting if these were accompanied by expressions of shame, rather than guilt (Giner-Sorolla, Castano, Espinosa, \& Brown, 2008; see also Giner-Sorolla, Kamau, \& Castano, 2010; Kamau, Giner-Sorolla, \& Zebel, 2013). This suggests that emotional expressions can be driven not only by the appraisals of the current situation but also by the need to communicate certain positions to the outgroup.

Matters are complicated by the fact that both expressing and decoding emotions might depend on group membership. For example, in a study reported by Leyens, Demoulin, Desert, Vaes, and Philippot (2002) participants' emotional expressions were judged as more accurate when their audience were other ingroup (rather than outgroup) members. This suggests that even if changes in appraisals induce more emotions that are potentially constructive for the reconciliation process, these might not always be accurately communicated to members of the outgroup. Furthermore, research by the same team indicate that people are less accurate in decoding emotions expressed by outgroup (vs. 
ingroup) members. There is also evidence for a tendency to attribute stereotypical emotions to outgroup members (Yabar \& Philippot, 2006). This might have important consequences for the reconciliation process. For instance, research by Wohl, Hornsey, and Bennett (2012) indicates that the success of intergroup apologies depends on emotional expressions. In a series of studies conducted in Canada and the United States, apologies accompanied by secondary emotions, such as shame, were less successful than those accompanied by primary emotions, such as sadness. One explanation for this effect can be derived from research on infrahumanization. Because outgroup members are attributed less secondary emotions, they might be perceived as less genuine when expressing these emotions in an apology.

Taken together, this research indicates that people's emotional reactions might not be readily communicated in the intergroup context, with obstacles arising both at the expression and decoding stages. Thus, even if levels of emotions such as hate or anger are successfully decreased, this change might not be readily communicated between two parties engaged in a conflict. Similarly, even if we successfully elicit collective guilt or shame, expressing these emotions to outgroup members might backfire, for example, by being perceived as dishonest and thereby decreasing intergroup trust.

\section{Conclusion}

The current review of the three additional functions of emotions beyond appraisal, as proposed by functional conflict theory, suggest that research on reconciliation processes might need to go beyond understanding of the appraisal process. Future studies would do well to consider the role of associative and group-regulatory processes that might sometimes override the appraisal processes. It also seems necessary to understand not only how to affect felt emotions but also how to facilitate their effective communication 
in order to achieve social change as well as harmonious intergroup relations. Although the authors' target article intentionally focuses on a small facet of an admittedly very complex process of group emotional regulation, we hope that these observations help theory and research in this area to grow in a direction perhaps not foreseen by their perspective.

\section{References}

Allpress, J. A., Brown, R., Giner-Sorolla, R., Deonna, J. A., \& Teroni, F. (2014). Two faces of group-based shame: Moral shame and image shame differentially predict positive and negative orientations to ingroup wrongdoing. Personality and Social Psychology Bulletin, 40, 1270-1284. http://dx.doi.org/10.1177/0146167214540724

Carver, C. S., \& Scheier, M. F. (1990). Origins and functions of positive and negative affect: A control-process view. Psychological Review, 97(1), 19-35.

Ĉehajić, S., Effron, D., Halperin, E., Liberman, V., \& Ross, L. (2011). Affirmation, acknowledgment of ingroup responsibility, group-based guilt, and support for reparative measures. Journal of Personality and Social Psychology, 101, 256-270. http://dx.doi.org/10.1037/a0023936

Cichocka, A., Marchlewska, M., Golec de Zavala, A., \& Olechowski, M. (2015). “They will not control us": In-group positivity and belief in intergroup conspiracies. British Journal of Psychology. http://dx.doi. org/10.1111/bjop.12158

Cichocka, A., Golec de Zavala, A., Marchlewska, M., Bilewicz, M., Jaworska, M., \& Olechowski, M. (2016). Personal control increases secure but decreases narcissistic ingroup positivity. Manuscript submitted for publication. 
Cichocka, A., Golec de Zavala, A., Marchlewska, M., \& Olechowski, M. (2015). Grandiose delusions: Collective narcissism, secure in-group identification and belief in conspiracies. In M. Bilewicz, A. Cichocka, \& W. Soral (Eds.), The psychology of conspiracy (pp. 42- 61). London, UK: Routledge.

Duval Smith, A. (2016, February). Polish move to strip Holocaust expert of award sparks protests. The Guardian. Retrieved from http://www.the guardian.com/

Finell, E., \& Zogmaister, C. (2015). Blind and constructive patriotism, national symbols and outgroup attitudes. Scandinavian Journal of Psychology, 56, 189-197. http://dx.doi.org/10.1111/sjop.12193

Frank, R. H. (1988). Passions within reason: The strategic role of the emotions. New York, NY: W. W. Norton.

Fujita, K., Trope, Y., Liberman, N., \& Levin-Sagi, M. (2006). Construal levels and selfcontrol. Journal of Personality and Social Psychology, 90, 351-367. http://dx.doi.org/10.1037/0022-3514.90.3.351

Gaertner, S. L., \& Dovidio, J. F. (2000). Reducing intergroup bias: The common ingroup identity model. New York, NY: Routledge.

Giner-Sorolla, R. (2012). Judging passions: Moral emotions in persons and groups. London, UK: Psychology Press.

Giner-Sorolla, R., Castano, E., Espinosa, P., \& Brown, R. (2008). Shame expressions reduce the recipient's insult from outgroup reparations. Journal of Experimental Social Psychology, 44, 519-526. http://dx.doi. org/10.1016/j.jesp.2007.08.003 
Giner-Sorolla, R., Kamau, C. W., \& Castano, E. (2010). Guilt and shame through recipients' eyes: The moderating effect of blame. Social Psychology, 41, 88-92. http://dx.doi.org/10.1027/1864-9335/a000013

Goldberg, J. H., Lerner, J. S., \& Tetlock, P. E. (1999). Rage and reason: The psychology of the intuitive prosecutor. European Journal of Social Psychology, 29, 781-795. http://dx.doi.org/10.1002/(SICI)1099-0992 (199908/09)29:5/63.0.CO;2-3

Golec de Zavala, A., \& Cichocka, A. (2012). Collective narcissism and anti- Semitism in Poland. Group Processes and Intergroup Relations, 15, 213-229. http://dx.doi.org/10.1177/1368430211420891

Golec de Zavala, A., Cichocka, A., Eidelson, R., \& Jayawickreme, N. (2009). Collective narcissism and its social consequences. Journal of Personality and Social Psychology, 97, 1074-1096. http://dx.doi.org/10.1037/ a0016904

Golec de Zavala, A., Cichocka, A., \& Iskra-Golec, I. (2013). Collective narcissism moderates the effect of in-group image threat on intergroup hostility. Journal of Personality and Social Psychology, 104(6), 1019-1039. http://dx.doi.org/10.1037/a0032215

Greenaway, K. H., Cichocka, A., van Veelen, R., Likki, T., \& Branscombe, N. (2016a). Feeling hopeful inspires support for social change. Political Psychology, 1, 89-107. http://dx.doi.org/10.1111/pops.12225

Greenaway, K. H., Cichocka, A., van Veelen, R., Likki, T., \& Branscombe, N. (2016b). Inclusive hope expressions increase support for social change. Manuscript in preparation.

Greenaway, K. H., Quinn, E. A., \& Louis, W. R. (2011). Appealing to common humanity increases forgiveness but reduces collective action among victims of historical atrocities. European Journal of Social Psychology, 41, 569-573. http://dx.doi.org/10.1002/ejsp.802 
Higgins, E. T. (1987). Self-discrepancy: a theory relating self and affect. Psychological Review, 94, 319-340.

Hodson, G., \& Costello, K. (2007). Interpersonal disgust, ideological orientations, and dehumanization as predictors of intergroup attitudes. Psychological Science, 18, 691698. http://dx.doi.org/10.1111/j.1467- 9280.2007.01962.x

Inbar, Y., Pizarro, D. A., Knobe, J., \& Bloom, P. (2009). Disgust sensitivity predicts intuitive disapproval of gays. Emotion, 9, 435. http://dx.doi. org/10.1037/a0015960

Jostmann, N. B., \& Koole, S. L. (2009). When persistence is futile: A functional analysis of action orientation and goal disengagement. In G. B. Moskowitz \& H. Grant (Eds.), The psychology of goals (pp. 337-361). New York: Guilford.

Kamau, C., Giner-Sorolla, R., \& Zebel, S. (2013). Reconciliation responses, blame, and expressions of guilt or shame. Journal of Applied Social Psychology, 43, 287-292. http://dx.doi.org/10.1111/jasp.12048

Leach, C. W., Zeineddine, F. B., \& Ĉehajić -Clancy, S. (2013). Moral immemorial: The rarity of self-criticism for previous generations' genocide or mass violence. Journal of Social Issues, 69, 34-53. http://dx.doi.org/ 10.1111/josi.12002

Leidner, B., Castano, E., Zaiser, E., \& Giner-Sorolla, R. (2010). Ingroup glorification, moral disengagement, and justice in the context of collective violence. Personality and Social Psychology Bulletin, 36, 1115-1129. http://dx.doi.org/10.1177/0146167210376391

Leyens, J. P. H., Demoulin, S., D_esert, M., Vaes, J., \& Phillipot, P. (2002). Expressing emotions and decoding them: In-groups and out-groups do not share the same advantages. In D. Mackie \& E. Smith (Eds.), From prejudice to intergroup emotions: 
Differentiated reactions to social groups (pp. 135-151). Philadelphia, PA: Psychology Press.

Lickel, B., Steele, R. R., \& Schmader, T. (2011). Group-based shame and guilt: Emerging directions in research. Social and Personality Psychology Compass, 5, 153-163.

Morton, T. A., \& Postmes, T. O. M. (2011). Moral duty or moral defence? The effects of perceiving shared humanity with the victims of ingroup perpetrated harm. European Journal of Social Psychology, 41, 127-134. http://dx.doi.org/10.1002/ejsp.751

Myrseth, K. O. R., \& Fishbach, A. (2009). Self-control a function of knowing when and how to exercise restraint. Current Directions in Psychological Science, 18, 247-252. http://dx.doi.org/10.1111/j.1467- 8721.2009.01645.x

Roccas, S., Klar, Y, \& Liviatan, I. (2006). The paradox of group-based guilt: Modes of national identification, conflict vehemence, and reactions to the in-group's moral violations. Journal of Personality and Social Psychology, 91, 698-711. http://dx.doi.org/10.1037/0022- 3514.91.4.698

Shah, J. Y. (2005). The automatic pursuit and management of goals. Current Directions in Psychological Science, 14, 10-13. http://dx.doi.org/ 10.1111/j.0963-7214.2005.00325.x

Tapias, M. P., Glaser, J., Keltner, D., Vasquez, K., \& Wickens, T. (2007). Emotion and prejudice: Specific emotions toward outgroups. Group Processes \& Intergroup Relations, 10(1), 27-39. doi:10.1177/1368430207071338

Vallacher, R. R., \& Wegner, D. M. (1987). What do people think they're doing? Action identification and human behavior. Psychological Review, 94, 3-15. http://dx.doi.org/10.1037/0033-295X.94.1.3 
Wohl, M. J., Hornsey, M. J., \& Bennett, S. H. (2012). Why group apologies succeed and fail: Intergroup forgiveness and the role of primary and secondary emotions. Journal of Personality and Social Psychology, 102, 306-322. http://dx.doi.org/10.1037/a0024838

Yabar, Y., \& Philippot, P. (2006). Friends or foes: Stereotyping and affective reactions to ingroup versus out-group members (Working Papers No. 2-06). Lower Hutt, New Zealand: The Open Polytechnic of New Zealand. 